\title{
A Technique to Monitor the Real-Time Proton Leak Status of Cells
}

\author{
Karen Poon ${ }^{1}$, Yuan Yizhi ${ }^{1}$, Baliji B Prasath ${ }^{1}$ and Ruihua Wang ${ }^{2 *}$ \\ ${ }^{1}$ Program of Food Science and Technology, BNU-HKBU United International College, China \\ ${ }^{2}$ Department of Gastroenterology, Shenzhen Hospital of Southern Medical University, China
}

Received: November 08, 2017; Published: November 15, 2017

*Corresponding author: Ruihua Wang, Department of Gastroenterology, Shenzhen Hospital of Southern Medical University, Shenzhen 518100, China, Tel: (86) 756-3620621; Email: ruihuawang@vip.163.com

\section{Introduction}

Proton leak was a detour of protons from their original path leading to the reduction of mitochondrial membrane potential. It leads to the decrease of ATP production per glucose molecule. It is a form of energy loss [1]. Proton leak was found to reduce the reactive oxygen species (ROS) level [2]; therefore, it plays a role in aging [3], diet [4-5] and health [6-9]. A method to monitor the real-time proton leak in cells would help for the understanding of physiological system and disease conditions. When protons were leaked out from mitochondria, it increased the leaking of electrons from electron transport chain [10]. The leaked electron would generate electric signal in Microbial Fuel Cells (MFC). Measuring the electric signal sent out during the process of proton leak would be a way to quantify thereal-time status of proton leak in live cells. Theoretically, higher the electric signal means higher is the proton leak. However, the accuracy of MFC measurements is influenced by the internal resistance of the apparatus. The internal resistance is contributed by the activation loss from electron transfer from cells to the anode, the characteristics of cellular metabolism, the flux of reactants and ohmic loss [11].

Activation loss and cellular metabolism are cell-specific, while flux of reactants and ohmic loss arise more from the MFC equipment and operating conditions, for example the resistance of the electrodes and membrane, the conductivity of the electrolyte solutions and the quality of the electrical contacts [12]. However, the measurement of internal resistance was very time consuming. Therefore, experiments were done to see if there was correlation between electric current with and without correction.

\section{Methods}

MFC has two chambers, a cathode and an anode, that are separated by a proton exchange membrane. The cathode was filled with $100 \mathrm{ml}$ of $50 \mathrm{mM}$ potassium ferricyanide (III) $\left(\mathrm{C}_{6} \mathrm{~N}_{6} \mathrm{FeK}_{3}\right)$ to function as an electron acceptor, while $100 \mathrm{ml}$ of isolated cells $(4 \mathrm{x}$
$10^{7}$ cells $/ \mathrm{ml}$ ) were added to the anode as electron donors. Nitrogen gas was pumped into the anode chamber for $5 \mathrm{~min}$ to remove oxygen from the headspace of the anode. A carbon electrode was placed in each chamber connected with external wire that are connected with a digital multi-meter (Tektronix DM4020, USA) to monitor the open circuit voltage (EMF) across the electrodes. Current I, without correction for internal resistance, was calculated using equation 1 with an external resistance $\left(\mathrm{R}_{\text {ext }}\right)$ of $1000 \Omega$.

$$
E M F=I R_{\text {ext }}(1)
$$

The internal resistance of the MFC was determined in a closedcircuit arrangement shown in Figures 1\&2. Closed circuit voltages were measured in different external resistance of $3,000 \Omega, 2,000 \Omega$, $1,000 \Omega, 800 \Omega, 600 \Omega, 400 \Omega$ or $200 \Omega$. Using the equation 1 , the corresponding electric currents were calculated. A polarization curve, that was a plot of electric current with voltage, was generated, and the internal resistance $\mathrm{R}_{\text {int }}$ was determined by the slope of the regression [11]. Electric current with the correction of internal resistance was calculated as in equation 2 .

$$
E M F=I\left(R_{i t t}+R_{e x t}\right)(2) \text { (Figure 1) }
$$

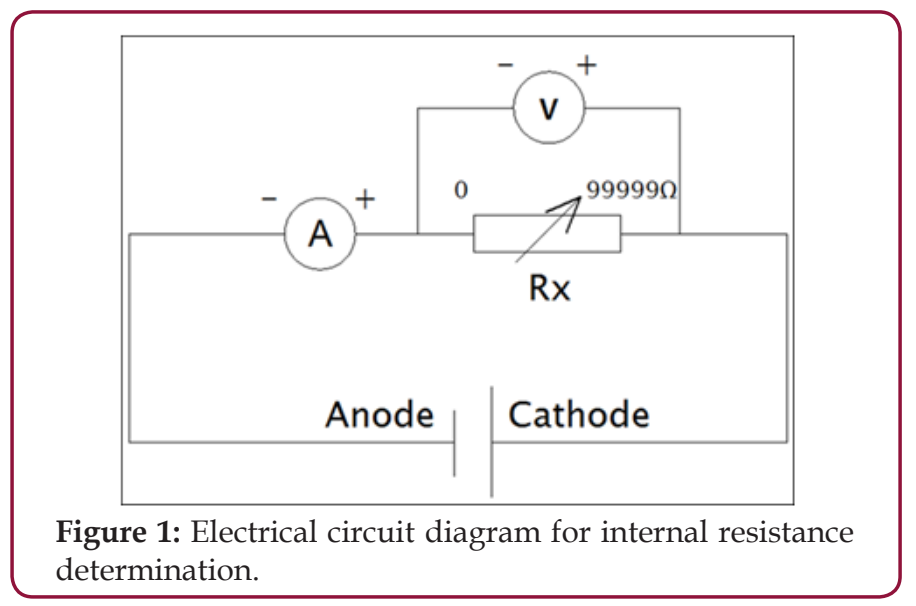




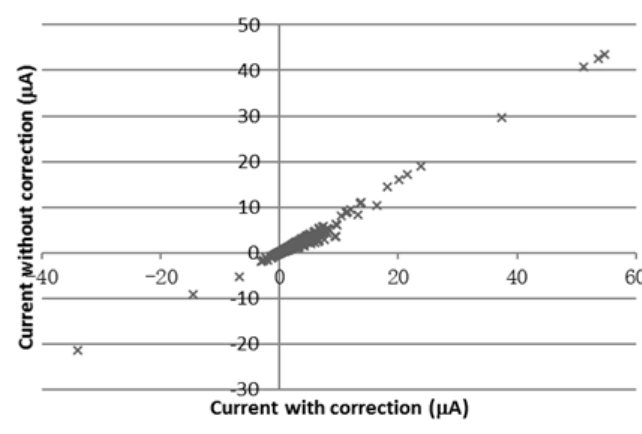

Figure 2: Plot of electric current without corrected with internal resistance versus electric current with correction (correlation coefficient $=0.9913$ ).

\section{Result and Conclusion}

A good correlation was observed between electric current with or without correction (Figure 2). It indicated that it was possible to use the electric current without correction to correlate with the degree of proton leak in cells. When the experimental conditions were consistently controlled, the changes in electric signal should reflect to the biological changes in cells. In this experiment, 30-minute survival was good for the hepatocytes the cells used in the studies, which further supports the use of MFC in monitoring the proton leak status of live cells. The present technique had advantages over other chemical testing method, because it provided instantaneous information on metabolic changes in tissues.

\section{Acknowledgement}

Authors would like to thank UIC College Research Grant R201620 for supporting this project.

\section{References}

1. Hoefnagels M (2015) Biology: concepts and investigations 3rd edition published by McGraw-Hill Education, New York, USA.
2. Bevilacqua L, Ramsey JJ, Hagopian K, Weindruch R, Harper M (2005) Long-term caloric restriction increases UCP3 content but decreases proton leak and reactive oxygen species production in rat skeletal muscle mitochondria. American Journal of Physiology - Endocrinology and Metabolism 289: E429-E438.

3. Asami DK, McDonald RB, Hagopian K, Horwitz BA, Warman D, et al. (2008) Effect of aging, caloric restriction, and uncoupling protein 3 (UCP3) on mitochondrial proton leak in mice. Exp Gerontol 43 (12): 1069-1076.

4. Ruiz-Ramírez A, Chávez-Salgado M, Peñeda-Flores JA, Zapata E, Masso F, et al. (2011) High-sucrose diet increases ROS generation, FFAaccumulation, UCP2 level, and proton leak in livermitochondria. Am J Physiol Endocrinol Metab 301(6): E1198-E1207.

5. Bevilacqua L, Ramsey JJ, Hagopian K, Weindruch R, Harper ME (2004) Effects of short and medium term calorie restriction on muscle mitochondrial proton leak and reactive oxygen species production. Am J Physiol Endocrinol Metab 286(5): E852-E861.

6. Poon K, Liang L, Xu C, Wang R (2016) The use of microbial fuel cells to monitor the current production in Qi-deficient liver cells. Journal of traditional Chinese medicine 32(2): 231-237.

7. Aguer C, Pasqua M, Thrush AB, Moffat C, McBurney M (2013) Increased proton leak and SOD2 expression in myotubes from obese non-diabetic subjects with a family history of type 2 diabetes. Biochim Biophys Acta 1832:1624-1633.

8. Quarrie R, Cramer BM, Lee DS, Steinbaugh GE, Erdahl W, et al (2011) Ischemic preconditioning decreases mitochondrial proton leak and reactive oxygen species production in the postischemic heart. J Surg Res 165(1): 5-14.

9. Wang R, MoYung KC, Zhao YJ, Poon K (2016) A mechanism for the temporal potentiation of Genipin to the cytotoxicity of Cisplatin in colon cancer cells. International Journal of Medical Sciences 13(7): 507-516.

10. Wang R, MoYung KC, Zhang MH, Poon K (2015) UCP2- and non UCP2mediated electric current in eukaryotic cells exhibits different properties. Environmental Science and Pollution Research 22(24): 19618-19631.

11. Li LH, Sun YM, Yuan ZH, Kong XY, Li Y (2013) Effect of temperature change on power generation of microbial fuel cell. EnvironTechnol 34(13/14): 1929-1934.

12. Logan B (2008) In microbial fuel cell. John Wiley \& Son, Inc.2008, New Jersey, USA.

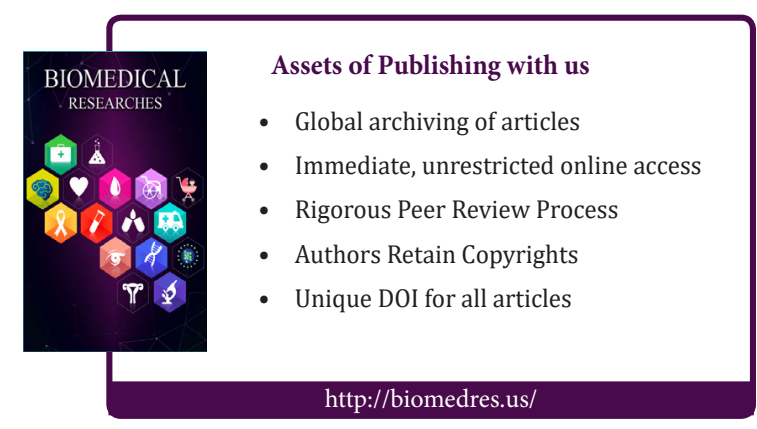

